\title{
A TUTELA DA CRIANÇA INTERSEX: UMA ANÁLISE PRINCIPIOLÓGICA
}

\section{Andréa Santana Leone de Souza ${ }^{1}$ Mônica Neves Aguiar da Silva ${ }^{2}$}

\section{RESUMO}

O presente artigo visa discutir os princípios e regras constitucionais na perspectiva da tutela da criança intersex. Para Tanto, procedeu-se com a revisão de literatura, através do levantamento de artigos, livros, periódicos sobre a temática, e revisão legislativa. A doutrina majoritária percebe a importância da análise principiológica para responder às demandas de uma sociedade complexa, plural e diversa. No que tange as crianças intersex percebe-se que os princípios são fundamentais à sua proteção, diante da ausência de normas que tratem sobre o tema. Neste cenário, é preciso chamar a atenção do poder legislativo de que urge a necessidade de uma ordem normativa que acompanhe as demandas da sociedade.

PALAVRAS-CHAVE: Princípios; Regras; Direitos Humanos; Intersex; Criança.

\section{INTERSEX CHILD CARE: A PRINCIPLED ANALYSIS}

\begin{abstract}
This article aims to analyze and discuss the principles and constitutional rules in view of intersex children's protection. Therefore, it was proceeded with literature review, articles' surveys, books, journals on the subject, and legislative review. The majority doctrine realizes the value of principled analysis to answer the demands of a complex, plural and diverse society. Regarding children with intersex it is understood that the principles are fundamental to their protection, facing the lack of rules that address on the topic. In this scenario, it is necessary call the legislature's attention for the urgency of a normative order to monitor the society's demands.
\end{abstract}

KEY-WORDS: Principles, Rules, Human Rights, Intersex; Child.

\section{INTRODUÇÃO}

A intersexualidade constitui uma situação de natureza interdisciplinar que interessa a algumas áreas da medicina - endocrinologia, urologia, genética, pediatria, entre outras- assim como à bioética, à psicologia, à saúde coletiva e ao próprio direito. Os primeiros artigos sobre a temática remontam de mais de cinco décadas.

\footnotetext{
${ }^{1}$ Professora da Universidade Federal do Oeste da Bahia. Mestra em Relações Sociais e Novos Direitos pela Universidade Federal da Bahia. E-mail: andrealeoneadv@gmail.com.

${ }^{2}$ Professora da Universidade Federal da Bahia. Doutora em Direito das Relações Sociais pela Pontifícia Universidade Católica de São Paulo. E-mail: monicaaguiarpsi@ gmail.com.
} 
Partindo da análise de uma sociedade complexa e diversa (MIALLE, 2005, p.21), em todos os sentidos, o presente artigo visa analisar e discutir os princípios e regras constitucionais na perspectiva da tutela da criança intersex.

Para isso, adotou-se um método com abordagem de natureza qualitativa de forma a buscar o fortalecimento da compreensão sobre a temática eleita (MYNAIO, 2006). Optou-se por diversos procedimentos, tais como revisão de literatura, levantamento de bases legislativas, levantamento de projetos de lei e levantamento de jurisprudências.

Para tanto, o artigo iniciará com o conceito de intersexo, com o objetivo de iniciar a aproximação com o tema e demonstrar a complexidade que circunda a temática. Analisará os princípios e regras constitucionais na perspectiva da tutela da criança intersex, e a importância do Direito em estar sempre alerta à pluralidade da sociedade, visando garantir direitos, respeitar diferenças e assegurar o respeito à alteridade.

No âmbito das ciências sociais aplicadas, o tema "criança com intersexo" ainda é pouco suscitado. O interesse em tratar do tema surgiu após aprofundado levantamento de artigos, constatando-se que os trabalhos publicados abordam a temática a partir de perspectivas diversas das que privilegiam a garantia dos princípios e regras constitucionais para a tutela da criança com intersexo.

Essa questão anseia por efetivo debruçar-se do Poder Público, cujas políticas devem visar à proteção da criança com intersexo. Para isto, é necessária não só movimentação da sociedade civil, mas também da academia, responsável por estudos aprofundados que, muitas vezes, servem de base para políticas públicas.

\section{2- INTERSEXO}

A intersexualidade constitui-se como resultado de um desequilíbrio entre os fatores que determinam o sexo (SUTTER, 1993). Dessa forma, os indivíduos apresentam caracteres tanto masculinos quanto femininos (VILAR, 2009). O desequilíbrio ocorre de 01 em cada 4.500 nascimentos (VILAR, 2009), sendo fundamental para sua detecção precoce o cuidadoso exame dos genitais de todo recém-nascido (DAMIANI;GUERRA-JUNIOR,2007).

$\mathrm{Na}$ literatura sobre o tema, o termo "intersexo" está em desuso, pois traria um sentido intermediário ou de um terceiro sexo, o que não seria adequado para o paciente (DAMIANI; GUERRA-JUNIOR,2007), passando a ser nomeado como Anomalia do Desenvolvimento 
Sexual (ADS) ou Desordem do Desenvolvimento Sexual (DDS) (DAMIANI; GUERRAJUNIOR, 2007). No presente artigo, porém, dialoga-se com o modelo social de deficiência, que reconhece o corpo com impedimentos como uma expressão da diversidade humana e não apenas como resultado de um diagnóstico biomédico de "anomalias" (DINIZ; SANTOS, 2009). De onde se entende que as nomenclaturas ADS ou DDS transmitiriam uma ideia de que a intersexualidade seria resultado de "anomalias" ou "desordens", reforçando o estigma sobre as pessoas com intersexo (DAMIANI;GUERRA-JUNIOR, 2007). Optou-se pelo termo "intersexo" em face do tensionamento entre as opções supra, advindas da Endocrinologia Pediátrica.

O estigma em relação às pessoas com intersexo é um assunto delicado. O tratamento médico pode vir a se prolongar, em algumas circunstâncias, durante a existência da pessoa, com a necessidade de realização de exames, da utilização de medicamentos e, em alguns casos, da realização de cirurgias corretivas (GUERRA-JUNIOR; MACIEL-GUERRA, 2007). A pessoa com intersexo ainda tem que enfrentar o preconceito social e cultural perante a sua situação, assim como a ignorância e invisibilidade, que ainda pairam sobre o assunto no meio acadêmico e cientifico (GUERRA-JUNIOR; MACIEL-GUERRA, 2007).

Diante de todas estas barreiras, o Conselho Federal de Medicina (CFM), em 2003, emitiu a Resolução 1664, que trata do intersexo e propõe, entre outras medidas, que a criança com intersexo seja considerada caso de urgência médica e social, cujo tratamento deve ser buscado em tempo hábil, de forma a garantir a dignidade da pessoa humana, princípio basilar dos Direitos Humanos.

No que tange a posição tomada pela equipe multidisciplinar em face da criança com intersexo, aponta Machado(2005) queesta posição é tomada a partir do entrelaçamento dos dados apontados pela equipe multidisciplinar e pela família, destacando que:

"no que se refere à cirurgia, a principal preocupação é com o resultado 'estético' ou 'cosmético' dos genitais construídos. As técnicas cirúrgicas são empregadas no sentido de tornar a genitália da criança 'o mais próximo possível do normal', de acordo com determinados padrões de tamanho, forma, 'terminação do trajeto urinário' (mais na ponta do pênis para os meninos; mais abaixo nas meninas) e uso (construir vaginas 'penetráveis' e pênis 'que penetrem')"(MACHADO, 205, p.4/5)

Posição esta confrontada pelo IntersexSocietyof North America (ISNA), cuja missão é impedir a "correção" da genitália na criança, por entender ser uma atitude precoce. Afirmando 
que a justificativa de que para os pais seria uma situação mais confortável, demonstra-se fragilizada, uma vez que a angústia, o sentimento evidenciado pelos pais de crianças com intersexo, mantém-se de qualquer forma.

$\mathrm{Na}$ tentativa de dialogar os posicionamentos divergentes, observa-se a Autonomia Familiar, princípio que proporcionaria a liberdade aos pais no exercício do poder familiar, segundo Delgado, em confronto com a autonomia privada da criança, fruto de uma luta histórica para alcançar o entendimento de sujeito de direito.

\section{3- OS DIREITOS HUMANOS E OS PRINCÍPIOS CONSTITUCIONAIS}

LuisRecasensSiches (1959) anota que os direitos do homem, antes tratados como um mito político,passaram, após a Segunda Guerra Mundial, a ter uma grande importância prática, revelada com a Carta das Nações Unidas, que veio afirmar a preocupação em garantir a efetividade dos direitos humanos. Consoante o mencionado autor, a Declaração Universal dos Direitos do Homem (DUDH), proclamada em 1948, visando dar efetividade às disposições da Carta das Nações Unidas, representa o dever do estado em converter os direitos "ideais" em direitos subjetivos dentro do ordenamento jurídico positivo.

A DUDH, como assevera o mencionado autor (SICHES, 1959), garante a dignidade da pessoa humana como atributo inseparável aos membros da família humana, que implica diretamente na concretização do princípio da liberdade individual. Orienta Borges (2007) que a inserção do princípio fundamental da dignidade humana na Constituição Federal de 1988 implica ganho de sua força vinculante e obrigatoriedade de sua carga axiológica.

Para SOARES (2010, p.37), o mencionado princípio se "desdobra em inúmeros outros princípios e regras constitucionais, conformando um arcabouço de valores e finalidades a ser realizadas pelo Estado e pela sociedade civil”. Ressalta que estes valores são utilizados como base para concretizar os direitos fundamentais que estão garantidos na Carta Magna, e, ainda, nas normas infraconstitucionais (SOARES, 2010, p.137).

"Direitos humanos fundamentais" seriam direitos institucionalizados que visam garantir o respeito à dignidade do ser humano na concepção de Moraes (2011). Na atual concepção jurídica de pessoa humana, bastaria possuir a qualidade de ser humano para que o 
ordenamento jurídico reconhecesse a qualidade de digno (BORGES, 2007). Esse princípio refletiria, então, uma conquista do homem.

$\mathrm{Na}$ acepção de Immanuel Kant (2003), o conceito de dignidade estaria estreitamente vinculado ao conceito de liberdade, pois a autonomia seria essencial para a dignidade da pessoa humana. Neste diapasão, afirma Sarlet (2011) que a garantia do direito à liberdade é o fundamento principal para a concretização da dignidade, ressaltada a importância de garantir a dignidade da pessoa humana ao absolutamente incapaz. Essa posição é defendida por Aftalión, Olano e Vilanova (1956), para quem o direito à liberdade (direito à vida, à integridade corporal, à liberdade etc.) seria um direito subjetivo, que dependeria da vontade do titular para sua garantia e efetividade.

Autonomia privada, segundo Borges (2007), seria um dos princípios fundamentais do direito privado, em que o poder seria atribuído pelo ordenamento jurídico aos sujeitos; e essa delimitação do "poder" visaria garantir os interesses sociais e assegurar a dignidade da pessoa humana. Para Meireles, o princípio da Autonomia Privada apresentar-se-ia como verdadeiro instrumento de promoção da personalidade (MEIRELES, 2007). Dentro da esfera da autonomia privada, os atos individuais de autonomia constituiriam "expressão da vontade como meio de desenvolvimento da personalidade do declarante" (MEIRELES, 2007, p.77).

Como garantia do princípio da dignidade da pessoa humana, o princípio da Não Discriminação, inserido no texto da DUDH, opera como condição e pressuposto para o pleno exercício dos Direitos Humanos nele enunciados (MEIRELES,2007, p.77). Esse princípio suporta alta carga garantistado princípio da Isonomia na atuação da proteção da criança com intersexo, que ainda tem de ser percebida como igual às outras crianças. Ou seja, deve ser concebida como "ser humano, devendo ter sua integridade e desenvolvimento assegurados"(CANGUÇU-CAMPINHO,2008,p.1158). Adverte, Boaventura de Sousa Santos (2003), que "as pessoas e os grupos sociais têm o direito de ser iguais quando a diferença os inferioriza, e o direito a ser diferente, quando a igualdade os descaracteriza".

Preocupando-se com a condição peculiar da criança, a Convenção dos Direitos da Criança (CDC) (ONU, 1989), adotada pela Assembleia Geral das Nações Unidas em 20 de novembro de 1989, garante medidas adequadas para que não haja discriminação, bem como, para conceder ajuda apropriada aos pais na educação de seus filhos (ONU, 1948).

Seus princípios norteadores estão elencados nos artigo, $2^{\circ}, 3^{\circ}, 6^{\circ}$ e $12^{\circ}$ sendo eles, respectivamente, o da não discriminação; do melhor interesse da criança, direito de 
sobrevivência da vida e desenvolvimento e o respeito pelas opiniões das crianças (ONU, 1948). Neste sentido, constitui um robusto instrumento de proteção da criança com intersexo.

Ainda paira uma clássica distinção, como assevera Delgado (2006), que separa os Direitos Humanos e os direitos fundamentais dos direitos da personalidade: os dois primeiros como direitos públicos e os últimos como direitos privados. Essa classificação acarreta dificuldades para a proteção plena da pessoa humana, haja vista a inviabilidade de entender a complexidade e o alcance dos direitos da personalidade em função de sua restrição à concepção privada, sem que sejam vinculados aos direitos humanos e aos direitos fundamentais. Neste sentido, Oliveira e Muniz garantem ser necessário "vincular a noção de direitos da personalidade à noção de direitos do homem" (OLIVEIRA;MUNIZ, 1980, p.228) com o fito de conferir a real amplitude aos direitos da personalidade.

Os direitos fundamentais possuem características comuns que os identificam, tais como: Historicidade, Universalidade, Inalienabilidade, Imprescritibilidade, Irrenunciabilidade, Interdependência e Indivisibilidade (CUNHA-JUNIOR, 2008). Tais características alinham-se com as características dos direitos da personalidade, que seriam, segundo Orlando Gomes (1996), imprescritíveis, intransmissíveis, impenhoráveis, extrapatrimoniais, absolutos, vitalícios e necessários. Ao analisar ambas as características em conjunto, percebe-se uma complementaridade entre os direitos fundamentais e os direitos da personalidade. Para Canotilho (2003), os direitos fundamentais, cada vez mais, tendem a ser direitos de personalidade e vice-versa. Acrescenta Groeninga(2003) que os direitos da personalidade representariam uma proteção ao indivíduo de qualquer ato que venha pôr em risco sua integridade física ou moral.

Os direitos da personalidade não constituem rol taxativo de acordo com Borges (2007), mas uma série aberta de direitos, com fundamento no artigo $5^{\circ}$, parágrafo $2^{\circ}$, da Constituição Federal, que garante a proteção de qualquer situação que venha a expor a dignidade da pessoa humana. A autora entende que a impossibilidade de exaurir as possíveis violações aos direitos da personalidade decorreria da evolução e constante mutação da sociedade que geram situações inéditas demandando a proteção do Estado.

Miguel Reale (2013), ao tecer considerações sobre o novo Código Civil, ressalta a importância da adequação das transformações históricas de uma determinada sociedade, contribuindo para as modificações dos direitos da personalidade, vinculando, neste sentido, cada direito da personalidade com um valor fundamental diverso, para cada civilização. 
Pablo StolzeGagliano e Rodolfo Pamplona Filho entendem como direitos da personalidade aqueles que visam à proteção dos atributos "físicos, psíquicos e morais da pessoa em si e em suas projeções sociais" (2011, p.180), classificando estes direitos em: proteção à vida e a integridade física (corpo vivo, cadáver, voz); proteção à integridade psíquica e criações intelectuais (liberdade, criações intelectuais, privacidade, segredo); integridade moral(honra, imagem, identidade pessoal) (GAGLIANO; PAMPLONA, 2011, p.193).

Os direitos da personalidade estão categorizados por Orlando Gomes (1966) como: Direito à Integridade Física, subdividido em direito à vida, direito sobre o próprio corpo e direito ao cadáver - e Direito à Integridade Moral - que se subdivide em direito a honra, direito a liberdade, direito a imagem, direito ao nome e direito moral do autor.

Para Francisco Amaral, os direitos da personalidade tutelam os direitos subjetivos, e visa a proteção "de valores essenciais da pessoa, no seu aspecto físico, moral e intelectual" (AMARAL,2008,p.283). Assim sendo, classifica-os como: direito à integridade física (direito à vida e direito ao próprio corpo), direito à integridade intelectual (direito autoral) e direito à integridade moral (direito à identidade pessoal, direito à honra, direito ao recato, direito a imagem e direito ao nome). (AMARAL, 2008)

\section{1- DISTINÇÃO ENTRE PRINCÍPIOS E REGRAS}

Entende Bobbio (2010, p. 15) que "a melhor maneira de se aproximar da experiência jurídica e compreender seus traços característicos é considerar o direito como um conjunto de normas, ou regras de conduta.". Assim, o mencionado autor entende que diante de uma norma jurídica pode-se questionar sobre a eficácia, justiça e validade (BOBBIO, 2010,p. 37).

No que tange a eficácia, o mencionado autor ressalta que deve ser analisada desde o comportamento da sociedade e dos seus interesses, a partir da análise histórica e sociológica de um determinado local, para que desta forma seja possível evidenciar a aplicação destas normas jurídicas (BOBBIO, 2010, p.44). Este autor vai informar que esta mudança de perspectiva para a análise do direito se justifica a partir da percepção de que o direito consuetudinário surge como expressão das necessidades de um povo, que muitas vezes não é 
expressa diante do direito imposto pelo "grupo dominante", representado pela lei (BOBBIO, 2010, p.56)

No mesmo sentido,Engisch entende que apesar das técnicas elementares de interpretação, sendo elas: gramatical, sistemática, teleológica, utilizadas para sanar alguma questão duvidosa, é de suma importância que o jurista ao interpretar desperte para uma análise extensiva, que englobe todo o contexto filosófico, político e cultural, visando a real compreensão contextualizada da lei (ENGISCH, 2001 p.148/149)

Engisch (2001, p. 38) divide o estudo em direito subjetivo e direito objetivo, entendendo direito subjetivo como o poder ou legitimação conferida pelo Estado e o direito objetivo fundamentado em regras jurídicas, que abrange a noção de norma jurídica atributiva. Compreende que as regras jurídicas "exprimem uma vontade da comunidade jurídica do Estado ou do legislador. Esta se dirige a uma determinada conduta dos súditos, exige esta conduta com vistas a determinar a sua realização"(ENGISCH, 2001, p. 38)

Ressalta o autor que, em um momento anterior,consolidou-se a ideia de que normas deveriam expressar uma clareza e segurança jurídica absoluta, garantindo uma decisão judicial que não coubesse interpretação divergente, assim uma concepção de que o juiz seria o “escravo da lei”. Com a crise do positivismo e com a percepção de que as leis precisariam corresponder às demandas de uma sociedade cada vez mais dinâmica, os tribunais foram se "libertando" e passaram a ter mais autonomia para interpretar a lei em conformidade com o contexto social da época(ENGISCH, 2001, p.207).

Ressalta Soares (2010) que, o então denominado "neoconstitucionalismo", representou a manifestação da crise do positivismo e a instauração do pós-positivismo jurídico, foi calcado na reaproximação das Constituições de substrato ético dos valores sociais e abriu“"espaço para o reconhecimento da força normativa da Constituição e de uma nova interpretação constitucional de base principiológica"(SOARES, 2010, p.126).

Os conceitos jurídicos indeterminados e as cláusulas gerais são expressões da aquisição da autonomia do órgão julgador em face da legislação. Entende Engisch (2001, p.208) que estes conceitos trazem como característica a incerteza de sua medida e da sua extensão.

Ressalta Neves (2018) que: 
Enquanto os princípios abrem o processo de concretização jurídica, instigando, à maneira de Hidra, problemas argumentativos, as regras tendem a fechá-lo, absorvendo a incerteza que caracteriza o início do procedimento de aplicação normativa. A incerteza é qualificada, e a complexidade torna-se relativamente estruturada (ou estruturável) por força dos princípios jurídicos, pois eles dão certos contornos e pontos de referência- ancorados em expectativas normativas presentes na sociedade e nos diretamente envolvidos no processo - à discussão travada na busca de solução do caso, mas só as regras viabilizam a transformação da incerteza do ponto de partida à certeza obtida com a decisão. Só a regras levam à redução de complexidade ou à seleção suscetível de determinar a solução do caso.(NEVES, 2013, p.18)

Para o mencionado autor, diante da distinção entre princípios e regras, é necessário iniciar a discussão pelo debate de tipos normativos, para desta forma ser possível a sua caracterização. Neste sentido, entende que os princípios e as regras situam-se "no plano da norma (do significado), entre os planos do texto normativo (significante) e do fato jurídico (referente)" (NEVES, 2013, p.5)

Orienta Ávila (2008) que "as regras possuem um elemento frontalmente descritivo, ao passo que os princípios apenas estabelecem uma diretriz" (ÁVILA, 2008,p.40). Ressalta que, apesar deste caráter "absoluto" das regras ao contextualizá-las, diante das considerações específicas de cada caso, é possível perceber que a sua destinação pode ser completamente modificada.

Tanto os princípiosquanto as regras, consoante Neves (2013), tratam de normas abstratas e o que as diferenciam é o grau de generalidade e abstração. Entende que os princípios expressam em seu conteúdo a "expectativas normativas com pretensão de validade moral, valores- preferência ou valores:identidade de grupos"(NEVES, 2013, p.128).

Segundo Neves (2013), esta expressão valorativa, em muitos casos, apresenta-se de forma conflituosa, pois ao analisar o contexto sociocultural de uma determinada sociedade, estes valores se diferenciarão a depender do grupo, justificado pela existência de uma sociedade divergente e plural. Assim, ressalta que é incontestável a importância dos princípios para flexibilizar os entendimentos e trazer a melhor resposta que se adeque caso a caso, mas que é necessário ter limite diante da utilização destes, como justificativa, para que não reflita uma insegurança jurídica “incontrolável”, bem como, não se deve utilizar de forma excessiva as regras, para não limitar a interpretação e desta forma não ser possível resolver os 
problemas sociais complexos. Neste sentido, propõe que para a melhor resolução de um “caso" será necessário a ponderação entre o uso dos princípios e o uso das regras (NEVES, 2013).

\section{4- A TUTELA DA CRIANÇA INTERSEX: UMA ANÁLISE PRINCIPIOLÓGICA}

O pós-positivismo atribuiu força aos princípios jurídicos, mesmo ao perceber as dificuldades diante da elasticidade de seus conteúdos e da indeterminação do alcance. Justificado pela necessidade de interpretar e aplicar o Direito que corresponda às demandas de uma sociedade plural e complexa. (SOARES, 2010, p.113).

Esta percepção da importância da análise principiológica a partir de uma determinada norma é percebida no capítulo II, dos Direitos da personalidade, do código Civil de 2002, especificamente no art.13, no qual se garante, ressalvado exigência médica, a proibição da “disposição do próprio corpo, quando importar diminuição permanente da integridade física, ou contrariar os bons costumes".

Frise-se que apesar deste artigo, hoje, se encontrar superado, sendo possível a cirurgia de transgenitalização, ou nos casos das crianças com intersexo, a cirurgia de definição do sexo, estas condutas são permitidas tomando como justificativa a ressalva do Código Civil, analisando o caso a partir de uma exigência médica, não privilegiando o entendimento de autonomia privada ou mesmo de dignidade da pessoa humana.

Entende Borges (2007) que a reflexão sobre "direito ao próprio corpo" e sobre a "autonomia privada" deve ser orientada por três artigos da Constituição Federal, sendo eles: o artigo $1^{\circ}$, inciso III, que garante a dignidade da pessoa humana; o artigo $5^{\circ}$, caput, que garante a inviolabilidade do direito à vida e do direito à liberdade; e o artigo $4^{\circ}$, que traz a disponibilidade de partes do corpo.

Assim, a mencionada autora, conforme entende Neves (2013), parte de uma análise orientada basicamente a partir dos princípios, analisando a complexidade dos fatos e permitindo um fundamento substancial de conteúdo flexível que deverá se adequar a depender do caso em tela.

Ressalte-se, ainda, que a lei $\mathrm{n}^{\circ}$ 6.015, de 31 de dezembro de 1973, que dispõe sobre registros públicos, em seu artigo 54, impõe, dentre os requisitos para o registro do nascimento o sexo e o prenome. Assim, dentre os atributos necessários para o assentamento do registro 
civil, temos o nome e o sexo como dois entraves para o registro da criança com intersexo, e, por conseguinte para o exercício da cidadania.

$\mathrm{O}$ registro civil de nascimento é um direito fundamental de todos e também uma obrigação legal dos pais, do Estado e da sociedade, de acordo com o art. 227 da Constituição Federal, in verbis: "é dever da família, da sociedade e do Estado assegurar à criança, ao adolescente e ao jovem, com absoluta prioridade, o direito à vida, à saúde, à alimentação, à educação, ao lazer, à profissionalização, à cultura, à dignidade, ao respeito, à liberdade e à convivência familiar e comunitária, além de colocá-los a salvo de toda forma de negligência, discriminação, exploração, violência, crueldade e opressão" (grifo nosso).

Para Pablo StolzeGagliano e Rodolfo Pamplona Filho, o direito à identidade tem como objeto a proteção dos "elementos distintivos da pessoa, natural ou jurídica, no seio da sociedade" (GANGLIANO; PAMPLONA, 2011). Assim, visa à proteção do direito ao nome.

No que tange ao direito à identidade, Francisco Amaral entende que o mesmo integra a noção de direito à integridade moral, diante da importância do reconhecimento de uma pessoa a partir de uma denominação própria (AMARAL, 2008).

Anderson Schreiber reforça que "o nome representa bem mais que o sinal de reconhecimento do seu titular pela sociedade: o nome estampa a própria identidade da pessoa humana" (SCHREIBER, 2011, p.205). E afirma que, esta denominação própria representa um sistema complexo de situações que interferem integralmente na vida do ser humano.

Explica Maria Celina Bodin (2000), que foi por entender esta importância que a doutrina italiana desenvolveu a noção de direito à identidade pessoal, que vai transbordar a tutela do direito ao nome, e alcançar as inúmeras situações decorrentes deste direito.

Reforça a mencionada autora que para a conceituação deste direito à identidade será necessário abranger duas instâncias: a estática e a dinâmica. Assim, "a identidade estática compreende o nome, a origem genética, a identificação física e a imagem; a identidade dinâmica se refere à verdade biográfica, ao estilo individual e social da pessoa, isto é, àquilo que a diferencia e singulariza" (MORAES, 2000, p.72).

Os supracitados autores destacam a importância do nome como forma de reconhecimento da personalidade da pessoa humana, que contribui para a efetividade da sua dignidade. Neste ponto encontra-se o registro civil como necessário ao exercício da cidadania, conforme a Lei $\mathrm{n}^{\circ}$. 9.534, de 10 de dezembro de 1997, que impõe a gratuidade deste serviço, independentemente da capacidade econômico-financeira dos interessados. 
Projeto de lei, encabeçado pelos Deputados Federais Jean Wyllys e Érica Kokay (2013), tem como objetivo garantir o direito a identidade de gênero a toda e qualquer pessoa, e entende como identidade de gênero a forma como o individuo se reconhece perante a sociedade, visando garantir neste projeto, dentre outras coisas, a possibilidade de retificação do registro civil para readequação à identidade de gênero.

Ana Karina Canguçu-Campinho(2012) ressalta que, para as ciências sociais, a questão da criança com intersexo já não é tratada como uma patologia, mas como uma diversidade de sexo e gênero.

Neste sentido, percebe-se como fundamental para a tutela da criança com intersexo a análise casuística calcada nos princípios, justamente por se tratar de uma demanda complexa e por hoje não termos leis que tratem do tema, e, quando tratam, a exemplo do mencionado art. 13 do CC e da Lei de Registros Públicos, não refletem as necessidades das crianças com intersexo, nem priorizam a garantia da dignidade da pessoa humana.

Como garantia do princípio da dignidade da pessoa humana, o princípio da Não Discriminação, inserido no texto da DUDH, opera como condição e pressuposto para o pleno exercício dos Direitos Humanos nele enunciados (MEIRELES,2007, p.77). Esse princípio suporta alta carga garantista do princípio da Isonomia na atuação da proteção da criança com intersexo, que ainda tem de ser percebida como igual às outras crianças, ou seja, deve ser concebida como "ser humano, devendo ter sua integridade e desenvolvimento assegurados"(CANGUÇU-CAMPINHO,2008,p.1158). Adverte Boaventura de Sousa Santos (2003) que "as pessoas e os grupos sociais têm o direito de ser iguais quando a diferença os inferioriza, e o direito a ser diferente, quando a igualdade os descaracteriza".

Preocupando-se com a condição peculiar da criança, a Convenção dos Direitos da Criança (CDC) (ONU, 1989), adotada pela Assembleia Geral das Nações Unidas em 20 de novembro de 1989, garante medidas adequadas para que não haja discriminação, bem como, para conceder ajuda apropriada aos pais na educação de seus filhos (ONU, 1948).

Seus princípios norteadores estão elencados nos artigo, $2^{\circ}, 3^{\circ}, 6^{\circ}$ e $12^{\circ}$ sendo eles, respectivamente, o da não discriminação; do melhor interesse da criança, direito de sobrevivência da vida e desenvolvimento e o respeito pelas opiniões das crianças (ONU, 1948). Neste sentido, constitui um robusto instrumento de proteção da criança com intersexo.

A CDC alinha-se a este entendimento ao dispor, no artigo 23, que os Estados partesreconheçam que as crianças com necessidades especiais deverão desfrutar uma vida 
plena e decente em condições que garantam sua dignidade e que favoreçam, frise-se, sua autonomia e facilitem sua participação ativa (ONU, 1989).

Neste entendimento, Soares ressalta que "a violação de um princípio jurídico é algo mais grave do que a transgressão de uma regra jurídica. A inobservância de um princípio ofende não apenas um específico mandamento obrigatório, mas todo um plexo de comandos normativos"(SOARES, 2010, p.115).

Entende o mencionado autor que

o debate sobre a legitimidade do ordenamento jurídico remete à necessidade de fundamentar o Direito em padrões valorativos ou estimativas sociais, perquirindo as possibilidades de materialização da justiça. Direito justo é, portanto, o sinônimo de direito legítimo, porque capaz de espalhar, em certo ambiente histórico-cultural, os valores tendentes à concretização do valor do justo numa dada comunidade humana. (SOARES, 2010, p.23)

Assim, percebe-se que a interpretação a partir dos princípios permite a observância de uma sociedade complexa, plural e diversa, e, desta forma, possibilita a concretização e garantiada dignidade da criança com intersexo.

\section{5- CONCLUSÃO}

Através da revisão de literatura, percebeu-se que a doutrina se posiciona favorávelmente diante da importância da analise normativa a partir dos princípios, ressalvando que esta análise deve ser moderada, para evitar inseguranças jurídicas incontroláveis.

Todavia, a segurança jurídica não deve ser utilizada como argumento para a análise restrita da norma, justamente por não permitir a análise do caso a partir das suas singularidades e, assim, não perseguir a concretização da justiça.

Acerca da revisão legislativa, encontra-se a Declaração Universal de Direitos Humanos, a Convenção sobre os Direitos das Crianças e o Estatuto da Criança e do Adolescente, como pilares para a defesa dos direitos da criança com intersexo, tanto no que 
tange ao seu peculiar estado de desenvolvimento, como no que tange a necessidade de garantir a efetivação da sua dignidade, mas, para tanto, é preciso buscar a sua efetivação.

Neste ponto encontram-se o art. 13 do CC e a Lei de Registros Públicos, no que concerne à garantia da dignidade da pessoa humana, como normas de análise restrita e que não correspondem às demandas de uma sociedade complexa, diante do seu rigor excessivo, sendo necessário para tanto, a análise destas normas na perspectiva dos princípios e tendo como princípio basilar a dignidade da pessoa humana.

Neste cenário, é preciso investir em campanhas públicas educativas para combater à discriminação histórica da qual estas crianças são vítimas, bem como chamar a atenção do poder legislativo de que urge a necessidade de uma ordem normativa que acompanhe essas demandas da sociedade.

\section{6- REFERÊNCIAS}

AMARAL, Francisco. Direito civil: introdução,7.ed.rev.,atual.eaum.Rio de Janeiro. Renovar. 2008

ANDRADE, Andréa Gustavo Corrêa de. O Princípio Fundamental da Dignidade Humana e sua Concretização Judicial. In: Fórum Administrativo-Direito Público-ano 1, n.1, mar.2001.Belo Horizonte: Fórum, 2001.p.4394-4404.

ÁVILA, Humberto. Teoria dos Princípios: da definição à aplicação dos princípios jurídicos. $9^{\mathrm{a}}$ edição. São Paulo, 2008. Editora Malheiros.

AFTALIÓN,Enrique R.; OLANO, Fernando García, VILANOVA, José. Tomo I Nociones Preliminares Teoría General Del derecho. Librería "EL ATENEO” Editorial. 5.ed. Buenos Aires, 1956

BACON, Francis. NovumOrganum - As verdadeiras indicações acerca da interpretação da natureza. Tradução e Notas: José Aluysio Reis de Andrade. Disponível em<www.virtualbooks.com.br> . Acesso em: 5 set. 2013.

BITTAR, Carlos Alberto.Os Direitos da Personalidade e o projeto de código civil brasileiro. Revista de Informação Legislativa. Ano 15, nº 60. Out/Dez, 1978

BOBBIO, Norberto. Teoria geral do direito. Tradução Denise Agostienetti; revisão da tradução Silvana Cobucci Leite. -3 ed. - São Paulo: Martins Fontes, 2010.

BONTEMPO, A.G. Direitos as Crianças à Plena Fruição dos Direitos Econômicos, Sociais eCulturais: O direito a ter direitos no futuro. In: SARMENTO, D.; IKAWA, D.; PIOVESAN, F. Igualdade, Diferença e Direitos Humanos. Rio de Janeiro: Ed. Lúmen Júris, 2008. p.831855. 
BORGES, Roxana Cardoso Brasileiro. Direitos de personalidade e autonomia privada.2.ed.rev.São Paulo: Saraiva, 2007.-(Coleção Prof. Agostinho Alvim/coordenação Renan Lotufo)

BRASIL. Lei João W. Nery. Lei de Identidade de Gênero . Projeto de Lei no__2013. Dep. Jean Wyllys e Érica Kokay. Dispõe sob o direito à identidade de gênero e altera o artigo 58 da Lei 6.015 de 1973.Disponível em:

http://www.camara.gov.br/proposicoesWeb/prop mostrarintegra?codteor=1059446\&filename $=$ PL+5002/2013. Acesso em: 08 set. 2013.

BRASIL. Lei nº.015. Dispõe sobre os registros públicos e dá providências. Disponível em: <http://www.planalto.gov.br/ccivil_03/leis/16015.htm> Acesso em: 8 set. 2013.

CANGUÇÚ-CAMPINHO, Ana Karina Figueira. Aspectos da Construção da Maternidade em Mulheres com Filhos Intersexuais. 2008. Dissertação (Mestrado em Saúde Comunitária) - Instituto de Saúde Coletiva da Universidade Federal da Bahia, Salvador, Bahia, 2001

CANGUÇU-CAMPINHO, Ana Karina Figueira. A Construção Dialógica da Identidade em Pessoas Intersexuais: O X e o Y da questão. 2012. Tese (Doutorado em Saúde Pública).Instituto de Saúde Coletiva. Universidade Federal da Bahia, Salvador.

CANOTILHO, J.J. Gomes. Direito Constitucional e Teoria da Constituição. $7^{a}$ edição. Editora Almedina, 2003.

COSSIO, Carlos. La Valoracíon Jurídica y laCiencia Del Derecho. EdicionesArayú. Buenos Ayres.1954.

CUNHA-JÚNIOR, Dirley. Curso de direito constitucional. $2^{\mathrm{a}}$ edição.Editora Juspodivm,2008.

DAMIANI, Durval; GUERRA-JUNIOR, Gil. As novas definições e classificações dos estados intersexuais: o que o Consenso de Chicago contribui para o estado da arte?.ArqBrasEndocrinolMetab, São Paulo, v. 51, n. 6, Aug. 2007

DELGADO, Mário Luiz. Direito da Personalidade nas Relações de Família.In:Família e dignidade humana/V Congresso Brasileiro de Direito de Família; Rodrigo da Cunha Pereira.São Paulo; IOB Thomson, 2006.p.679-739.

DINIZ, Debora; BARBOSA, Lívia; SANTOS, Wederson Rufino dos. Deficiência, Direitos humanos e Justiça.Sur, Revista Internacional dos Direitos Humanos, São Paulo, v. 6, n. 11, dez. 2009.

DHANDA, Amita. Construindo um novo léxico dos direitos humanos: Convenção sobre os Direitos das Pessoas com Deficiências.Sur, Rev. int. direitos human., São Paulo, v. 5, n. 8, jun. 2008 . 
ENGISCH, Karl. Introdução ao pensamento jurídico. Lisboa: Fundação CalousteGulbenkian, 2001.

FRASER, Roberta Tourinho Dantas; LIMA, Isabel Maria Sampaio Oliveira. Intersexualidade e Direito à identidade: uma discussão sobre o assentamento civil de crianças intersexuais. Journal of Human Growth and Development. 2002; 22(3); p.358-366

FEYERABEND, Paul K. Contra o método.Tradução Cezar Augusto Mortari. São Paulo. Editora UNESP. 2007.

GAGLIANO,PabloStolze. Novo Curso de direito civil, volume I: parte geral.13.ed.São Paulo: Saraiva, 2011

GUERRA-JUNIOR, Gil; MACIEL-GUERRA, Andréa T.. O pediatra frente a uma criança com ambigüidade genital. J. Pediatr. (Rio J.), Porto Alegre, v. 83, n. 5, nov. 2007

GROENINGA, Giselle Câmara. O Direito à Integridade Psíquica e o Livre Desenvolvimento da personalidade. In: Família e dignidade humana/ V Congresso Brasileiro de Direito de Família; Rodrigo da Cunha Pereira. São Paulo: IOB Thomson, 2006.p 439-455.

GOMES, Orlando. Direito de Personalidade. Revista de Informação Legislativa. Setembro de 1966.

GROENINGA, Giselle Câmara. O Direito à Integridade Psíquica e o Livre Desenvolvimento da personalidade. In: Família e dignidade humana/ V Congresso Brasileiro de Direito de Família; Rodrigo da Cunha Pereira. São Paulo: IOB Thomson, 2006.p 439-455.

HEIDEGGER, Martin. Sobre a essência da verdade. São Paulo: Abril Cultural (Col. Os Pensadores), 1984.

IBGE.Instituto Brasileiro de Geografia e Estatística.Censo Demográfico 2010. Disponível em $<$ http://www.ibge.gov.br>

IntersexSocietyof North America.Disponível em <http://www.isna.org/>. Acesso em: 8 set. 2013

KANT,Immanuel.Fundamentação da Metafísica dos Costumes. São Paulo: Martin Claret, 2003.

KANT, Immanuel. Crítica da faculdade do juízo. Trad. Valério Rohden e Antônio Marques. 2. ed. Rio de Janeiro: Forense Universitária. 1995.

MACHADO, Paula Sandrine. "Quimeras" da ciência: a perspectiva de profissionais da saúde em casos de intersexo. Rev. bras. Ci. Soc., São Paulo, v. 20, n. 59, out. 2005 . Disponível em <http://www.scielo.br/scielo.php?script=sci_arttext\&pid=S0102-

$69092005000300005 \& \operatorname{lng}=$ pt\&nrm=iso>. 
acessosem 20 out. 2011. http://dx.doi.org/10.1590/S0102-69092005000300005

MEIRELES, Rose Melo Vencelau. Autonomia Privada e Dignidade Humana. Rio de Janeiro. Renovar, 2009.

MINAYO, Maria Cecília de Souza. O desafio do conhecimento: pesquisa qualitativa em saúde. 9. ed. São Paulo: Hucitec, 2006.

MIAILLE, Michel. Introdução Crítica ao Direito. $3^{\text {a }}$ edição. Lisboa: Editorial Estampa, 2005

MORAES,Maria Celina Bodin de. Sobre o Nome da Pessoa Humana. Revista da Emerj.v.3.n ${ }^{\circ}$ 12. 2000

MORAES, Alexandre de. Direitos Humanos Fundamentais. Teoria Geral, Comentário aos arts. $1^{\circ}$ a $5^{\circ}$ da Constituição da República Federativa do Brasil, doutrina e jurisprudência.9.ed.São Paulo. Atlas,2011.

NEVES, Marcelo. Entre Hidras e Hercules - princípios e regras constitucionais. São Paulo: Martins Fontes, 2013

OLIVEIRA, José Lamartine orrêa. MUNIZ, Francisco José Ferreira. O Estado de Direito e os Direitos da Personalidade. In: Revista da Faculdade de Direito da UFPR, nº 19, ano 19, Curitiba: UFPR, 1980.

ONU,Convenção sobre os Direitos das Pessoas com Deficiência, de 13 de dezembro de 2006.

ONU. Convenção sobre os Direitos das Crianças,de 20 de novembro de 1989.

ONU. Declaração Universal dos Direitos Humanos, de 10 de dezembro de 1948.

PARAENSE, Leandro Lopes Pontes. Direito à identidade sexual: o desencaixe jurídico-social do transexual. Revista do Programa de Pós-graduação em Direito da Universidade Federal da Bahia.n¹2.ando 2005. Salvador-Bahia.p.133-155p.137

PERELMAN, Chaïm. Lógica jurídica- Nova Retórica, 2a ed. Editora Martins Fontes; São Paulo, 2004

REALE,Miguel.Os Direitos da Personalidade. Disponível em www.miguelreale.com.br. Acesso em: 8 set. 2013

SARLET, Ingo Wolfgang. Dignidade da pessoa humana e direitos fundamentais na Constituição Federal de 1988.9.ed.rev.atual - Porto Alegre: Livraria do Advogado Editora, 2011. 
SANTOS, Boaventura de Sousa. Reconhecer para Libertar: os caminhos do cosmopolitismo multicultural. Rio de Janeiro: Civilização Brasileira, 2003.passim

SCHREIBER, Anderson. Direitos da Personalidade. São Paulo. Atlas.2011

SICHES, LuisRecasens. Tratado General de Filosofia Del Derecho.

Primeraedicion.EditorialPorrua, S.A. Mexico, 1959

SOARES, Ricardo Maurício Freire. O princípio constitucional da dignidade da pessoa humana. São Paulo: Saraiva, 2010.

SUTTER, Matilde Josefina. Determinação e mudança de sexo: aspectos médicos-legais. São Paulo: Ed. Revista dos Tribunais, 1993

TRIVIÑOS, A. N. S. Introdução à pesquisa em ciências sociais: a pesquisa qualitativa em educação. São Paulo: Atlas, 1987

VILAR, Lúcio. Endocrinologia clínica. editores associados Claudio Elias Kater. ET. AL. 4.ed. Rio de Janeiro: Guanabara Koogan, 2009 